\title{
Discussion on State Maintenance and Maintenance of Offshore Oil Power Equipment
}

\author{
Li Jiang ${ }^{1} \mathrm{Li} \mathrm{Yi}{ }^{1}$ Zhan Yanmin ${ }^{1}$ Yang $\mathrm{Xu}{ }^{2}$
}

\begin{abstract}
With the rapid development of social economy, power resources gradually become the cornerstone of economic development, and energy demand is increasing, and energy extraction depends on the support of power resources. The maintenance and maintenance of the state of electric power equipment have obviously improved the utilization rate of oil and the effect of production cost. It can be seen that the exploration and research on the state maintenance and maintenance of offshore oil and electric power equipment has important practical significance. This paper first introduces the meaning and development of state condition maintenance of electric power equipment, and then expounds the purpose and significance of state maintenance and maintenance of offshore oil and electric power equipment. Finally, a series of countermeasures are put forward for the problems existing in the maintenance and maintenance of offshore oil power equipment.
\end{abstract}

Key words: Offshore oil; electrical equipment; state maintenance; maintenance

\section{Introduction}

Nowadays, energy is one of the important elements of national development and social progress. It has a direct influence on the development of various fields. It is the foundation of human existence. However, energy extraction depends on the support of power resources. With the rapid development of social economy, power resources has gradually become the cornerstone of economic development,

2 CNOOC Energy Development Equipment Technology Co., Ltd. Tianjin 300452 and the increasing demand for energy, to some extent to promote the progress of the power industry, power technology is also increasingly sophisticated, the power industry on other areas of domestic development is not small Look at the impact. This paper first introduces the meaning and development of state condition maintenance of electric power equipment, and then expounds the purpose and significance of state maintenance and maintenance of offshore oil and electric power equipment. Finally, a series of countermeasures are put forward for the problems existing in the maintenance and maintenance of offshore oil power equipment.

\section{The meaning and development of state equipment maintenance}

\subsection{The meaning of state equipment maintenance}

The so-called state maintenance, is the use of equipment for testing and repair, and the previous cycle of maintenance is different from its data analysis based on the development of maintenance programs. The maintenance method is based on a large number of data information, analysis and processing to develop maintenance programs, data management is one of the core content of its development. In addition, the maintenance method into the Internet technology, power technology, data processing technology and other interdisciplinary, the general work flow chart shown in Figure 1 below.

1.2 Development of power equipment condition maintenance

Although the western developed countries have started from the 1970s on the state of power equipment maintenance and maintenance of the study and exploration, and made some progress, but the vast majority of the object is the power system power generation, power transmission and distribution aspects of the exploration not much. So far, China's power transmission and power supply and 


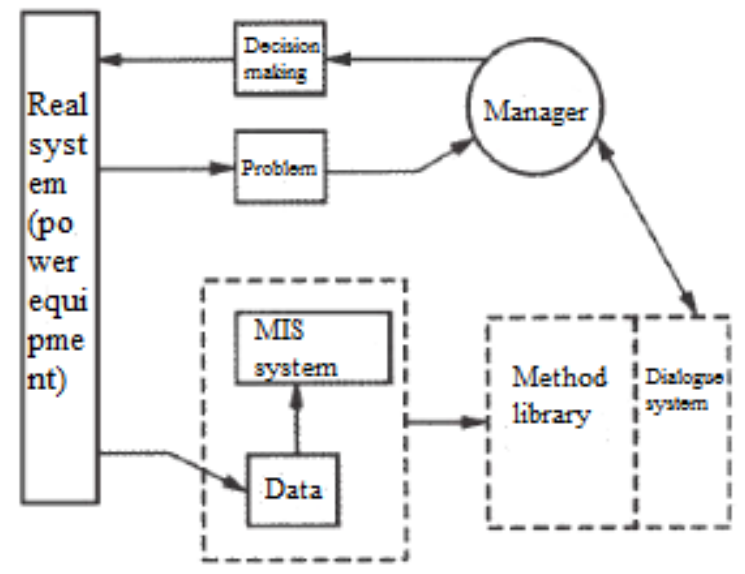

Figure 1 State of the power equipment maintenance DSS basic mode

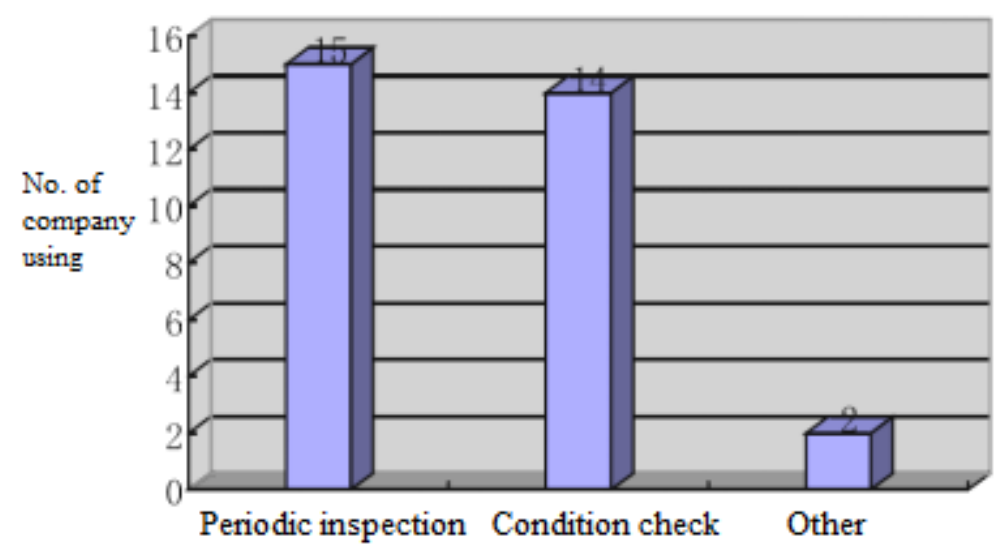

Figure 2 Power company now take the maintenance mode

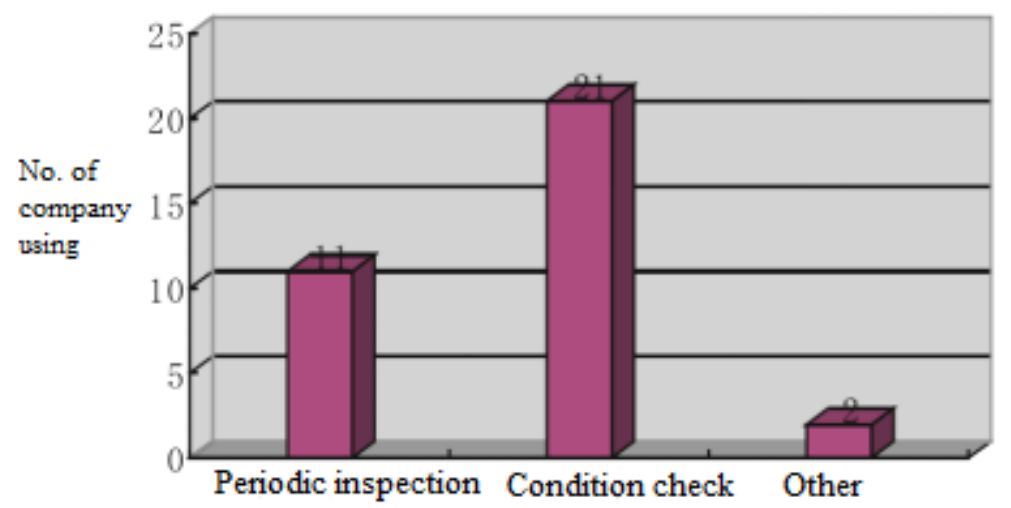

Figure 3 Power company will take the maintenance of the future

distribution aspects of the maintenance and maintenance work is also in the embryonic period. From the following chart can be more intuitive to see the state of power equipment maintenance status. 
Table 1 Summary of China's current maintenance form

\begin{tabular}{ll}
\hline Maintenance mode & Percentage/\% \\
\hline The use of regular testing of the main equipment, regular maintenance strategy & 26.0 \\
\hline The detection and maintenance of certain equipment has begun to adjust & 37.2 \\
\hline $\begin{array}{l}\text { The main equipment is gradually selected according to the actual situation of inspec- } \\
\text { tion and maintenance of the content and cycle }\end{array}$ & 27.0 \\
\hline $\begin{array}{l}\text { The main equipment has been fully realized according to the actual situation to select } \\
\text { the appropriate detection and maintenance content and cycle }\end{array}$ & \\
\hline
\end{tabular}

Table 2 China according to the specific circumstances of the development of maintenance cycle and methods of electrical equipment

\begin{tabular}{ll}
\hline Equipment type & Percentage/\% \\
\hline Main transformer & 50.0 \\
\hline Circuit breakers and GIS & 47.0 \\
\hline Transformers & 38.2 \\
\hline Capacitive equipment (capacitive casing and TA, coupling capacitors, etc.) & 32.4 \\
\hline Metal oxide surge arresters (MOA) & 52.9 \\
\hline
\end{tabular}

Table 3 China's maintenance program and the basis of time

\begin{tabular}{lc}
\hline Maintenance basis & Percentage/\% \\
\hline All by the provincial companies to develop temporary guidelines & 32.1 \\
\hline $\begin{array}{l}\text { In addition to the temporary guidelines established by the superior, the other part of } \\
\text { the supplementary provisions of the unit }\end{array}$ & 48.2 \\
\hline $\begin{array}{l}\text { Mainly by the Company in accordance with the relevant provisions of the provisions } \\
\text { of the actual situation }\end{array}$ & 19.7 \\
\hline
\end{tabular}

With the emergence of Internet technology and the general and perfect reform of the power system, the state of power equipment maintenance and maintenance has made a certain degree of progress, but also produced a related management and monitoring system. State Grid Corporation and its subsidiaries are actively carrying out the maintenance of the application of the promotion. In the future development of the domestic power industry, the state of power equipment maintenance and maintenance will inevitably be widely used to promote the creation of social and economic benefits to maximize.

2. The purpose, principle and significance of state maintenance and maintenance of offshore oil and

\section{electric power equipment}

\subsection{Purpose of implementation}

The maintenance and maintenance of the equipment and the maintenance of the equipment are carried out on-line or offline to carry out the testing and data analysis of the equipment. At the same time, the maintenance plan is developed in conjunction with the discovered problems and is regularly maintained during the use of the equipment to ensure the equipment is fully utilized and the equipment maintenance cost. According to the new management model, through a series of detection methods to monitor the analysis of power equipment, to keep abreast of equipment usage, real-time feedback equipment failure, and thus 
ensure the normal work of the equipment.

\subsection{Basic principles}

For the power equipment, the state maintenance and maintenance is a new maintenance system, vast project, advanced management, the current large companies in the country or the budding period. And offshore oil is one of the important domestic economic energy, in the current state maintenance and maintenance of the development conditions, the need to comply with the following principles:

2.2.1 Ensure that the electrical equipment is working properly

In terms of offshore oil extraction, the power equipment is an important condition for its production and production. It is the most basic constitution of the power system. The normal work of the equipment is an important guarantee for the production management. Thus, to ensure that the normal work of electrical equipment is the maintenance of the state and the maintenance of the primary principles.

\subsection{2 unified planning, and gradually implemented}

The maintenance and maintenance of electric power equipment is a more advanced management system. Before the implementation, it should be unified planning, adhere to the analysis and summary, and constantly improve, which depends on the overall planning under the premise of one by one implementation.

2.2.3 with the specific situation with fault detection equipment

In order to ensure the effective implementation of power equipment maintenance and maintenance, to ensure that the infrastructure is complete and adequate resources. Combined with the specific needs of offshore oil production and production, the maximum use of facilities and resources, planning and distribution of the state and the use of fault detection equipment is to ensure the accuracy of one of the important test results.

\subsection{Significant meaning}

2.3.1 The improvement of the power system depends on the effective maintenance and maintenance of the electrical equipment

On the current market economic system, the purpose of each company is the pursuit of social and economic interests, the current economic development of energy structure laid the power system can not be underesti- mated status, and enhance the efficiency of the power system operation, reduce operating costs is achieved The fundamental means of the above purposes. Among them, the state of power equipment maintenance and maintenance is to enhance the efficiency of the power system operating efficiency, reduce the operating costs of one of the main ways, we can see that its significance and role can not be underestimated.

2.3.2 State maintenance and maintenance of electrical equipment to maximize the use of resources to ensure the stability of power supply

Before the detection of electrical equipment to take basic maintenance and maintenance, that is, regardless of the actual work of electrical equipment, how are regular testing and maintenance, so often the detection time is not right, detection and other issues, leading to human, material and other resources insufficient. In addition, the periodic inspection and maintenance needs to plan power, the stability of the power supply has a great role. However, in the background of the continuous development of the offshore oil industry, the production rhythm of mining production, cyclical testing and maintenance caused by the power outage impedes the smooth production of oil, but the state maintenance and maintenance can effectively avoid these problems to ensure that the oil business social and economic benefits.

\section{Problems in Maintenance and Maintenance of Offshore Oil Power Equipment}

On the normal exploitation of offshore oil production, power system is an indispensable and important element, we can see, power equipment maintenance and maintenance needs to provide enough attention. So far, the state of oil and gas equipment maintenance and maintenance of its maintenance has a stable relay difficult, power equipment overload heat, harmonic pollution, voltage instability and a series of problems.

\section{1 maintenance of stable relay difficult}

The so-called offshore oil production process relay maintenance is stable, refers to the end of the load situation, the data processing to determine the corresponding load switch settings, and by assisting with the means to cut off the maintenance of short-circuit current. However, this method is easy to form a short circuit in the current, causing the rest of the break protection together, resulting in power system paralysis, increase the adverse effects of power failure.

\subsection{Power equipment overload heat}


Because the power system is too heavy load, the relevant parts of the contact is not good, parts are not fastened, resulting in the basic equipment connection is not normal heat phenomenon, causing rapid damage to parts damage, resulting in difficult to control the power accident, such as conductor melting, current short circuit trips, and even large fires.

\subsection{Harmonic pollution}

By the rapid development of industrial industry, the rapid increase in demand for electricity, power electronics and high-power switch in the basic use of oil production, so no accidentally produced a large number of harmonic pollution. In particular, many offshore oil power system harmonic pollution is particularly serious, much higher than China's limited standards, largely inhibited the progress and development of offshore oil industry.

\section{Effective measures for the problems of state maintenance and maintenance of offshore oil and electric power equipment}

On the work of offshore oil and electricity equipment, a series of problems, based on the rapid development of the oil industry to promote the goal of the effective implementation of the state of electrical equipment maintenance and maintenance. It is the key to ensure the smooth production, reduce the cost and enhance the utilization rate of the resources. At the same time, the fundamental goal of the state inspection and maintenance is to improve the economic benefits of the oil enterprises, and the specific interests of the oil companies. The measures are as follows:

4.1 State maintenance and maintenance of the first application of auxiliary power equipment, to be successful and then strengthen the promotion efforts

In terms of offshore oil and electricity equipment, in the detection and maintenance of major equipment, to abandon the traditional periodic inspection and maintenance, the implementation of advanced state maintenance methods, and do a good job of pre-maintenance and post-maintenance work, and gradually developed based on state maintenance mode of self-maintenance mode.

4.2 Improve the state detection and maintenance with data analysis technology

Effective and unified use of state detection maintenance methods and data analysis technology, to ensure the stability of the power equipment, to help enterprises to pursue social and economic profit maxi- mization, and for the improvement of power equipment to provide data analysis and support to reduce the current due to technological reform Adverse effects of technological change.

\section{Conclusion}

The so-called maintenance and maintenance of the state of the power equipment, in addition to a simple device testing, or an advanced management model and management tools to master, it is in the previous maintenance and maintenance on the way to create the reform. It can be seen that the exploration and research on the state maintenance and maintenance of offshore oil and electric power equipment has important practical significance.

\section{References}

[1] Wang Jiangping, Chen Wei, Xiao Dong, Peng Bin, Xie Xiao. Design of Data Table Structure for Condition Maintenance Test Project of Power Transmission and Transformation Equipment [J]. Automation \& Instrumentation 2010 (02)

[2] Sun Yue, Han Xu, Zhai Shuang, Liu Quanhe, Xiong Zhenlong. Application of Infrared Thermal Imaging Technology in Offshore Platform [J]. Automation and Instrumentation 2014 (09)

[3] Ping Chaochun. ETAP-Based Offshore Oil Engineering Power System Transient Stability Analysis [A] .2010 years of marine engineering conference proceedings [C]. 2010

[4] Li Yangsheng. Power Equipment Remote Control Method Analysis [J]. Automation and Instrumentation 2015 (06)

[5] Pan Yingju. Study on the Optimization and Simplification of the Ground System of the Former Large Oil Field $[A]$. Play the support of science and technology to promote the innovation and development in depth Proceedings of the 8th Annual Conference of Science and Technology of Jilin Province [C]. 2014

[6] Li Ningning, Zhang Wei, Yang Xiumei, Liu Hongbiao. Application of Outdoor Open-Type Electrical Appliances in Oilfield Substation [A]. To play the role of science and technology support to promote innovation and development - Jilin Province eighth science and technology academic conference Proceedings [C] .2014

[7] Li Jie, Hou Ying Sha, Zhao Jianli. Oil-immersed power transformer insulation condition of the recovery voltage method [J]. Automation and Instrumentation 


\section{$2015(05)$}

[8] Xie Jianrong, Chen Qingqi, Kuang Hongying, Duan Shousheng, Wang Lei, Huang Minjiang. Design of Infrared Temperature Online Monitoring Device for Power Equipment [J]. Automation \& Instrumentation 2012 (05)

[9] Xu Jianzhong, Yang Yueping, Pan Mingbo. Optimization of Power Equipment Maintenance Plan [J]. Electronic Technology and Software Engineering $.2013(15)$

[10] Cui Aichu, Cui Kedong, Cui Rose. Micro-power equipment maintenance plan optimization management [J]. China market .2015 (49)

[11] Ji Guoguo, Wu Wenchuan, Zhang Boming, Liu
Shungui, Jiang Wei. A Time-varying Downtime Model for Power Equipment for State Maintenance [J]. Proceeding of the CSEE, 2013 (25)

[12] Welte T.M. Using State Diagrams for Modeling Maintenance of Deteriorating Systems. IEEE Transactions on Power Systems.2009

[13] IEEE Guide for the Interpretation of Gases Generated In Oil-Immersed Transformers. IEEE Std C57.104TM-2008.2009

[14] Pathak J, Yong Jiang, Honavar V, et al. Condition data Aggregation with Application to Failure Rate Calculation of Power Transformers. Proceedings of the 39th Hawaii International Conference on System Sciences.2006 